\title{
Graduating MSW Students' Recommended Interventions for Teen Dating Violence: A Descriptive Analysis
}

\author{
Heidi Adams Rueda \\ Alicia Hawley \\ Beverly M. Black \\ Bernadette Ombayo
}

\begin{abstract}
Teen dating violence (TDV) is a widespread issue that social workers are likely to encounter in their practice with youth, yet little research exists concerning their preparedness to do so. This study assessed the proposed interventions of graduating MSW students $(n=73)$ from two accredited universities in response to two scenarios of TDV. Each scenario reflected various forms of violence. Nearly one-third of students' proposed interventions focused on the need to deliver some form of education, healthy relationships being the most prevalent theme. Other interventions included teaching about appropriate boundaries, issues of control and anger, self-esteem-building, and communication skills. The second most common set of responses pertained to individual assessment, and the third to individual and couple's counseling. Few comments identified specific TDV interventions, such as safety planning or evidence-based prevention programs. Students' recommendations for education and counseling rather than safety planning or multi-level interventions indicate that social work programs need to provide specific content in MSW curricula related to TDV and evidence-based interventions.
\end{abstract}

Keywords: Social work education, adolescent dating abuse, dating violence intervention, direct practice, school social work, qualitative methods

Data from the 2013 National Youth Risk Behavior Surveillance survey indicate that, of the nearly three-quarters $(73.9 \%)$ of high-school adolescents who had dated in the past year, one in five females and one in ten males had been physically and/or sexually assaulted (Vagi, Olsen, Basile, \& Vivolo-Kantor, 2015). Rates jump to approximately one-third of adolescents having experienced violence when psychological victimization is included in the measurement (Halpern, Oslak, Young, Martin, \& Kupper, 2001). Experiencing relationship violence during the adolescent years tends to correlate with a number of other risks, including higher rates of sexual intercourse, marijuana use, binge drinking, eating disorders, physical fighting, electronic bullying, and suicidality (Eaton, Davis, Barrios, Brener, \& Noonan, 2007; Silverman, Raj, Mucci, \& Hathaway, 2001; Vagi et al., 2015). Poor performance in school, decreased sense of self-worth, and depression are also associated with teen dating violence (TDV; Banyard \& Cross, 2008; Silverman et al., 2001).

Social workers serve youth in a variety of settings, underscoring the importance of being well-equipped with the necessary knowledge and skills to address TDV. However, very little is known about the extent to which graduating social work students in the U.S.

Heidi Adams Rueda, MSW, PhD is Assistant Professor, Department of Social Work, The University of Texas at San Antonio, San Antonio, TX, 78207. Alicia Hawley, MSSW, is a PhD Candidate, School of Social Work, The University of Texas at Arlington, Arlington TX, 76019. Beverly Black, Ph.D., MSSW, is Jillian Michelle Smith Professor in Family Violence Research, School of Social Work, The University of Texas at Arlington, 76019. Bernadette K. Ombayo, MSW, is a PhD Student, School of Social Work, The University of Texas at Arlington, 76019. 
are prepared to work with teens experiencing TDV, and in particular, how they would respond to youth approaching them about the issue. This article presents research on proposed interventions to scenarios of teen dating violence identified by advanced Master of Social Work (MSW) students in the southern United States.

\section{Literature Review}

Due to the lack of research concerning the preparedness of social workers to intervene specifically in situations of TDV, we draw on literature related to social workers and social work students' knowledge of and responses to intimate partner violence. We also draw upon the broader literature on helping professionals' knowledge of and responses to TDV.

\section{Social Work Education and Intimate Partner Violence}

For years, scholars have called for social work to provide more education on intimate partner violence (IPV) and to better prepare prospective social workers to effectively intervene (Connor, Nouer, Mackey, Banet, \& Tipton, 2012; Danis, 2004; McMahon, Postmus, Warrener, Plummer, \& Schwartz, 2013). However, we know that few students in the U.S. receive specific IPV education and training in their social work education. For example, Cohn, Salmon, and Stobo (2002) found that only 17 out of 74 reviewed MSW programs had a course on family violence. Further, Danis (2004) found that licensed social workers encountered abused women in their professional duties, yet over half reported little to no academic preparation on IPV. Postmus, McMahon, Warrener, and Macri (2011) found that only half of student respondents from a large MSW program had coursework that addressed domestic violence or sexual assault. In a somewhat more positive outcome, Connor et al. (2012) found that most (70\%) social work students had some form of IPV training during graduate school, with most reporting between one and five hours. These studies used different research methods making comparisons difficult; however, it appears as if there may be progress over time in exposure of MSW students to IPV education.

Research has also sought to understand whether social work education on IPV has had an impact on students, yielding mixed findings. McMahon and colleagues (2013) found that students in a specialized course on violence against women experienced a decrease in negative attitudes and beliefs concerning myths about survivors of sexual assault and domestic violence compared to students in Human Behavior in the Social Environment (HBSE) courses. Pomeroy et al. (2011) similarly found that specific attention to IPV in an introductory social work class helped students develop greater knowledge of IPV. In contrast, other studies have found that previous training and coursework have little impact on attitudes and beliefs about violence against women (Postmus et al., 2011; Tower, 2003) and raise concerns about students' readiness to intervene effectively with clients experiencing IPV. Black, Weisz, and Bennett's (2010) examination of social work students' probable interventions in response to a case scenario found that even though almost $20 \%$ of the students had taken an elective class on family violence, few mentioned IPV-specific interventions and one-third included statements that blamed the victim for the occurrence of violence. This study also found that a majority of students believed IPV to be a mental health issue and recommended counseling, an idea consistent with Danis and 
Lockhart's (2003) assertion that social work students view IPV as a mental health problem of the victim.

We do not know of any social work programs in the U.S. that offer a separate course on TDV. If social work students learn about TDV, the content is most likely incorporated in a course on domestic violence, family violence, or intimate partner violence. Some of the textbooks on domestic violence or family violence include a chapter on TDV (e.g., Barnett, Miller-Perrin, \& Perrin, 2010; Lockhart \& Danis, 2010), and a few of the commonly used HBSE textbooks include a short section on TDV (see for example, Hutchinson, 2008; Zastrow \& Kirst-Ashman, 2010). Students may also learn about TDV through field education. However, we know little about how social workers address TDV in their practice with youth.

\section{Helping Professionals' Roles and Knowledge Concerning TDV}

Helping professions are increasingly recognizing their roles in addressing TDV. In 2009, the American Academy of Pediatrics described pediatricians' roles as inclusive of preventing TDV through clinical services, advocacy, education, and in research practices. Each of these areas include screening, counseling, and maintaining an accurate communitybased referral list, as outlined in application of a specific protocol (Smith et al., 2009).

State policies have also identified school professionals as serving an important role in the provision of services to victims and perpetrators of TDV. As of November 2015, 22 states had passed TDV-specific laws regarding the development of school-based educational, counseling, safety, and other recommendations or requirements (National Conference of State Legislatures, 2016). In Texas, the state under study, districts are required to provide students with safety planning and counseling services, in addition to delineating a TDV policy and providing awareness education to students and teachers (Texas H.B. 121, 2007). A recent policy analysis revealed that, although most districts had offered a definition of TDV and associated consequences, services were often lacking, leading the authors to conclude that "as districts move forward in implementing the dating violence policy, emphasis must be placed on providing services to victims and increasing awareness" (Jackson, Bouffard, \& Fox, 2013, p. 524). By definition, school social workers often serve in the capacities described.

Despite the identified roles of helping professionals in addressing and preventing TDV, research on knowledge and preparedness concerning this issue is limited to two studies in nursing and counseling. In these national studies examining school counselors' $(n=305)$ and school nurses' ( $n=348)$ knowledge and training about TDV, and their ability to effectively intervene with youth experiencing it, Khubchandani et al. (2012) and Khubchandani, Telljohann, Price, Dake, and Hendershot (2013) found that although $61 \%$ of the counselors had assisted survivors of TDV in the past two years, $43 \%$ of the counselors had not received any training on TDV or how to intervene. Similarly, over half of school nurses had assisted a student with TDV, but $70 \%$ had no training on TDV. Counselors' and nurses' perceptions of TDV as a problem were correlated with the number of victims they had assisted. Of interest to the present study, school social workers were ranked as playing a significant role (second only to school counselors among a list of seven 
school-based professionals) in assisting adolescent survivors of TDV. As schools' and communities' awareness of TDV as an important and preventable health issue increases, social workers may be called upon with increasing frequency to deliver effective services to youth. In determining effectiveness, we direct the reader to other studies (see for example, de Koker, Mathews, Zuch, Bastien, \& Mason-Jones, 2014 for a review of TDV interventions), including those with emphasis on social work and perspectives from the field (e.g., Weisz \& Black, 2009).

Given that we know little about the extent to which MSW students in the U.S. are prepared to work with adolescents experiencing TDV, the purpose for this exploratory study was to assess the specific interventions graduating social work students recommend for adolescents experiencing dating violence. Understanding how recently graduated social workers approach situations of TDV can offer insights into curricular strengths and gaps for consideration among social work programs, as well as highlight how youth-serving agencies can provide relevant TDV training to social workers through comparison of students' recommended interventions to best practices.

\section{Methods}

A survey was administered across four semesters during the 2014-2015 school year to graduating MSW students in two universities, both located in the southern United States. One university has approximately $800 \mathrm{MSW}$ students and offers specializations in either direct clinical practice with families and children, mental health and substance abuse, aging, health, or in community and administrative practice. The other has approximately 240 students and has one advanced concentration in cultural competence. Students completed the survey online through SurveyMonkey. The survey was anonymous and took approximately 20 minutes to complete. In order to participate, students were required to be within one semester of graduating with the MSW degree. These students were invited to participate via a listserv invitation sent out from the administration offices of both schools, as well as via flyer invitations hung in the Social Work offices of both departments. At the conclusion of each semester's data collection, one student was chosen from each school at random to receive a $\$ 25$ gift card. A separate link within SurveyMonkey was provided at the conclusion of the survey where students could confidentially provide their email address for participation in this drawing. All research activities were approved by a centralized Institutional Review Board.

The survey included questions on the general demographic information of the participants, experiences serving youth, MSW coursework on TDV, and two vignettes reflecting commonly occurring TDV scenarios (see Appendix). This analysis focused on student responses to the two vignettes. The first and third authors developed the vignettes based on their previous experience with TDV research and prevention programs. The first vignette (Tiffany and Ana) pertained to a same-sex, female, high school couple in which one of the partners became possessive and controlling of the other. She began to demand increasing amounts of time and insisted on being together at the expense of her partner's extra-curricular activities. The student whose partner was behaving in a controlling manner approached the school social worker for help. The second vignette (Edgar and Angela) pertained to a heterosexual high school couple. The girlfriend became very jealous and 
violent in the relationship. After a heated argument in which she embarrassed her boyfriend in public and slapped his arm, the boyfriend pressured her to have unwanted sex with him. The girlfriend then approached the school social worker unsure of what to do. Each vignette was followed by an open-ended question: "How would you respond to this situation? Please be specific in describing the intervention(s) or series of interventions you feel would be most helpful."

\begin{tabular}{|c|c|}
\hline Characteristics $(n=73)$ & n $(\%)$ \\
\hline \multicolumn{2}{|l|}{ Gender } \\
\hline Female & $63(86.3 \%)$ \\
\hline Male & $10(13.7 \%)$ \\
\hline \multicolumn{2}{|l|}{ Race } \\
\hline Caucasian, non-Hispanic & $34(47.2 \%)$ \\
\hline Caucasian, Hispanic & $23(31.9 \%)$ \\
\hline African American & $8(11.1 \%)$ \\
\hline Asian & $3(4.2 \%)$ \\
\hline Mixed & $2(2.8 \%)$ \\
\hline Other & $2(2.8 \%)$ \\
\hline \multicolumn{2}{|l|}{ Sexual Orientation } \\
\hline Heterosexual/Straight & $66(90.4 \%)$ \\
\hline Gay & $4(5.5 \%)$ \\
\hline Bisexual & $2(2.7 \%)$ \\
\hline Lesbian & $1(1.4 \%)$ \\
\hline \multicolumn{2}{|l|}{ Age } \\
\hline $20-29$ & $42(57.5 \%)$ \\
\hline $30-39$ & $21(28.8 \%)$ \\
\hline $40-49$ & $9(12.3 \%)$ \\
\hline $50-59$ & $1(1.4 \%)$ \\
\hline \multicolumn{2}{|l|}{ Experience $(n=48)$} \\
\hline \multicolumn{2}{|c|}{ Ever worked with middle school or high school aged youth } \\
\hline Yes & $33(68.8 \%)$ \\
\hline No & $15(31.2 \%)$ \\
\hline \multicolumn{2}{|c|}{$\begin{array}{l}\text { MSW coursework included training on how to intervene with teens } \\
\text { experiencing dating violence }\end{array}$} \\
\hline Yes & $11(22.9 \%)$ \\
\hline No & $37(77.1 \%)$ \\
\hline
\end{tabular}

\section{Participants}

A total of 186 students completed the survey, $79 \%$ of who were from the larger of the two universities where the study took place. The survey was distributed over the course of four semesters ( $n=69$, spring of 2014; $n=13$, summer 2014; $n=49$, fall of $2014 ; n=55$, spring of 2015). A total of approximately 1016 students graduated over the course of survey administration, yielding a response rate of $18 \%$. Of these respondents, 73 students answered the open-ended questions pertaining to TDV vignettes. Approximately $86 \%$ of the respondents were female; $90 \%$ identified as heterosexual. Just under $50 \%$ were Caucasian, 32\% were Hispanic, and 11\% were African American. Over 50\% of the 
students surveyed were between the ages of 20-29. Nearly $70 \%$ indicated that they had experience working with middle or high-school aged youth, and approximately $30 \%$ reported formal coursework in their MSW program on how to intervene in situations of TDV (See Table 1).

\section{Analyses}

Utilizing Nvivo (Version 10), we conducted an inductive content analysis to delineate themes within participants' written responses to vignette questions. Following several thorough readings, the second author used open coding to assign independent conceptual ideas (e.g., safety planning, counseling) to all of the data for both scenarios (Creswell, 2007). These preliminary categories were then further refined and organized into meaningful themes and subthemes (e.g., "education" as a primary theme, "teaching coping techniques" as a subtheme). A codebook was devised to communicate the second author's operationalization of each theme and subtheme. This allowed the research team to evaluate the extent to which the themes and subthemes were clearly conceptualized and fit the data; several reiterations were made to the resultant codebook until agreement was reached. All of the data were then coded using the final codebook; comments that contained multiple classifications were coded into multiple themes or subthemes. This move from the raw data to more abstract levels of themes and subthemes is what allows for meaningful interpretation (Creswell, 2007). Finally, we calculated total frequencies by subtheme, theme, and vignette to allow for comparison.

\section{Results}

Students proposed a variety of intervention modalities in working with the dating couples. In order of prevalence, students recommended: 1) providing education, 2) counseling services, 3) conducting an assessment, 4) other (e.g., instituting a safety plan, notifying parents). See Table 2 for a full display of results and Table 3 for sample quotations. 
Table 2. Interventions for TDV Recommended by 73 MSW Students $(n=280) *$

\begin{tabular}{|c|c|c|c|}
\hline & Total n(\%) & $\begin{array}{c}\text { Vignette 1: } \\
\text { Tiffany \& Ana } \\
\text { n(\%) }\end{array}$ & $\begin{array}{c}\text { Vignette 2: Edgar } \\
\text { \& Angela } \\
\text { n(\%) } \\
\end{array}$ \\
\hline \multicolumn{4}{|l|}{ Education $(n=86,30.7 \%)$} \\
\hline Healthy/Unhealthy relationships & $25(29.1 \%)$ & $18(20.9 \%)$ & $7(8.1 \%)$ \\
\hline Boundaries & $11(12.8 \%)$ & $6(7.0 \%)$ & $5(5.8 \%)$ \\
\hline Control and anger & $11(12.8 \%)$ & $1(1.2 \%)$ & $10(11.6 \%)$ \\
\hline Self-worth/self-esteem & $10(11.6 \%)$ & $7(8.1 \%)$ & $3(3.5 \%)$ \\
\hline Communication & $9(10.5 \%)$ & $3(3.5 \%)$ & $6(7.0 \%)$ \\
\hline Sexual abuse & $8(9.3 \%)$ & & $8(9.3 \%)$ \\
\hline Birth control & $6(7.0 \%)$ & & $6(7.0 \%)$ \\
\hline Sexuality & $4(4.7 \%)$ & $2(2.3 \%)$ & $2(2.3 \%)$ \\
\hline Coping & $2(2.3 \%)$ & & $2(2.3 \%)$ \\
\hline Education Total & $86(100 \%)$ & $37(43.1 \%)$ & $49(56.9 \%)$ \\
\hline \multicolumn{4}{|l|}{ Counseling $(n=77,27.5 \%)$} \\
\hline Individual counseling & $34(44.2 \%)$ & $20(26 \%)$ & $14(18.2 \%)$ \\
\hline Couple's counseling & $13(16.9 \%)$ & $7(9.1 \%)$ & $6(7.8 \%)$ \\
\hline Group counseling & $8(10.4 \%)$ & $4(5.2 \%)$ & $4(5.2 \%)$ \\
\hline \multicolumn{4}{|l|}{ Specific counseling interventions } \\
\hline Solution-focused & $13(16.9 \%)$ & $9(11.7 \%)$ & $4(5.2 \%)$ \\
\hline Cognitive-behavioral & $6(7.8 \%)$ & $4(5.2 \%)$ & $2(2.6 \%)$ \\
\hline Role Play & $2(2.6 \%)$ & $1(1.3 \%)$ & $1(1.3 \%)$ \\
\hline Client-centered & $1(1.3 \%)$ & & $1(1.3 \%)$ \\
\hline Counseling Total & $77(100 \%)$ & $45(58.5 \%)$ & $32(41.5 \%)$ \\
\hline \multicolumn{4}{|l|}{ Assessment $(n=69,24.6 \%)$} \\
\hline Assess the goals for the relationship & $20(29 \%)$ & $13(18.8 \%)$ & $7(10.1 \%)$ \\
\hline Assess the overall situation & $17(24.6 \%)$ & $11(15.9 \%)$ & $6(8.7 \%)$ \\
\hline Explore feelings & $15(21.7 \%)$ & $1(1.4 \%)$ & $14(20.3 \%)$ \\
\hline Assess the home environment and past & $9(13.0 \%)$ & $6(8.7 \%)$ & $3(4.3 \%)$ \\
\hline Assess support systems & $5(7.2 \%)$ & $5(7.2 \%)$ & \\
\hline Assess impact on school performance & $3(4.3 \%)$ & $1(1.4 \%)$ & $2(2.9 \%)$ \\
\hline Assessment Total & $69(100 \%)$ & $37(53.4 \%)$ & $32(46.3 \%)$ \\
\hline \multicolumn{4}{|l|}{ Other $(n=48,17.1 \%)$} \\
\hline Safety plan & $22(7.9 \%)$ & $16(72.7 \%)$ & $6(27.3 \%)$ \\
\hline Notify parents & $11(3.9 \%)$ & $9(81.8 \%)$ & $2(18.2 \%)$ \\
\hline Referral & $9(3.2 \%)$ & $3(33.3 \%)$ & $6(66.7 \%)$ \\
\hline School interventions & $4(1.4 \%)$ & $4(100 \%)$ & \\
\hline Unsure & $2(0.7 \%)$ & & $2(100 \%)$ \\
\hline Other Total & $48(100 \%)$ & $32(66.7 \%)$ & $16(33.3 \%)$ \\
\hline
\end{tabular}


Table 3. Example Quotations

\begin{tabular}{|c|c|c|}
\hline Intervention & Total n & Example Quotations \\
\hline \multicolumn{3}{|l|}{ Education } \\
\hline Healthy/Unhealthy relationships & 25 & "Discuss what real love looks like" \\
\hline Boundaries & 11 & "Intervention regarding healthy boundaries would be implemented" \\
\hline Control and anger & 11 & "Brainstorm responses for Ana to the possessive behavior" \\
\hline Self-worth/self-esteem & 10 & "Provide Ana with education on self-esteem and self-confidence" \\
\hline Communication & 9 & "It appears that Edgar and Angela can learn to recognize their emotions and better communicate them" \\
\hline Sexual abuse & 8 & "Explain that there should never be pressure with sex" \\
\hline Birth control & 6 & "Discuss birth control options" \\
\hline Sexuality & 4 & "Teen sexuality should be addressed once the parents are involved" \\
\hline Coping & 2 & "I would coach her in calming techniques..." \\
\hline \multicolumn{3}{|l|}{ Counseling } \\
\hline Individual counseling & 34 & "Engaging with both clients first then some kind of individual counseling" \\
\hline Couple's counseling & 13 & "I would attempt to talk to both girls together in order to discuss what is going on and how they are bothered by it" \\
\hline Group counseling & 8 & "Group counseling or support groups to help both girls with similar issues they face" \\
\hline \multicolumn{3}{|l|}{ Specific counseling interventions } \\
\hline Solution-focused & 13 & "I think empowering the girls through individual solution-focused therapy would work well..." \\
\hline CBT & 6 & "Then I would work to correct the distorted thinking Ana has about her relationship with Tiffany by using CBT methods" \\
\hline Role Play & 2 & "Role-play ways in which Angela might verbalize her boundaries to Edgar" \\
\hline Client-centered & 1 & "I believe in this situation client centered could be a preferred theoretical technique" \\
\hline \multicolumn{3}{|r|}{ 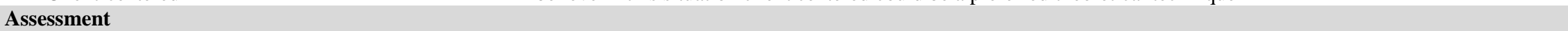 } \\
\hline Assess the goals for the relationship & 20 & "Discuss the idea of goals in the relationship" \\
\hline Assess the overall situation & 17 & "I would conduct a psychosocial evaluation on both girls individually" \\
\hline Explore feelings & 15 & "I would ask both of them to be completely honest and talk about their feelings and what has just happened" \\
\hline Assess the home environment and past & 9 & "I would assess her home life/history of abuse" \\
\hline Assess support systems & 5 & "Ask about parental or family support" \\
\hline Assess impact on school performance & 3 & "How is this relationship affecting grades?" \\
\hline \multicolumn{3}{|l|}{ Other } \\
\hline Safety plan & 22 & "I would first make sure she feels safe and then talk to her about how safe she feels staying in the relationship" \\
\hline Notify parents & 11 & "I believe parents need to be notified about situation" \\
\hline Referral & 9 & "Offer Ana resources that are available in the community and inform her that I am available should she need to talk" \\
\hline School interventions & 4 & "On a Macro level- teach school personnel to recognize the warning signs of teen dating violence..." \\
\hline Unsure & 2 & "I would research interventions for teen dating violence since I do not have a working base knowledge of TDV" \\
\hline $\mathbf{1 0 t}$ & 280 & \\
\hline
\end{tabular}




\section{Education}

The largest number of responses $(n=86 ; 30.7 \%)$ focused on some form of education that they would provide to the student(s). Recommendations addressing education focused on several specific areas including healthy/unhealthy relationships $(n=25 ; 29.1 \%$ of education responses), boundaries $(n=11 ; 12.8 \%)$, control and anger $(n=11 ; 12.8 \%)$, selfworth/self-esteem $(n=10 ; 11.6 \%)$, communication $(n=9 ; 10.5 \%)$, sexual abuse $(n=8$; $9.3 \%)$, birth control $(n=6 ; 7.0 \%)$, sexuality $(n=4 ; 4.7 \%)$, and coping $(n=2 ; 2.3 \%)$. Of these subthemes, the majority consisted of responses related to education on healthy/unhealthy relationships. Examples included:

I would provide psychoeducational information about healthy relationships.

I would let her know that she has the right to be in a relationship free from domestic violence and educate her on what healthy/unhealthy relationships looks like.

Examples of education on boundaries included:

Role play ways in which Ana might verbalize her boundaries to Tiffany.

Help her to outline her own personal emotional and physical boundaries so that she can feel less relationship pressure in the future.

Examples of statements made relating to control and anger included:

Address anger management issues.

Focus on techniques of addressing anger that encourage positive physical and emotional boundaries.

Additionally, MSW students recommended education regarding self-worth/self-esteem:

I would work with Ana to increase her self-esteem and work with Tiffany on her self-esteem, and relationship views.

I would help Angela in self-acceptance unconditionally for herself.

Finally, students offered recommendations with regard to teaching youth to improve their communication skills:

I would offer tools on how to effectively communicate with each other.

Discuss how Angela and Edgar are communicating; what is working and what is not.

\section{Counseling}

The second most common recommended intervention proposed was counseling ( $n=77$; $27.5 \%$ of total intervention responses). Almost half ( $n=34 ; 44.2 \%)$ of the recommendations about counseling specifically identified individual counseling. Additional counseling interventions proposed included couple's counseling ( $n=13 ; 16.9 \%)$, group counseling ( $n=8 ; 10.4 \%)$, and other specific counseling interventions. The specific counseling interventions that some of the MSW students proposed included: solution-focused ( $n=13$; 
$16.9 \%)$, cognitive-behavioral $(n=6 ; 7.8 \%)$, role-playing $(n=2 ; 2.6 \%)$, and client-centered $(n=1 ; 1.3 \%)$.

The following were some examples of individual counseling recommendations:

Individual counseling for both Tiffany and Ana.

Engaging with both clients first then some kind of individual counseling.

Examples of couple's counseling interventions included:

I would see if she would be okay if I can call Edgar in so that they can discuss their feelings with each other; being that they are both dealing with some issues.

I would ask them to come in for couple's therapy.

Group counseling recommendations included:

Psychoeducation group that focuses on healthy relationships, self-esteem, anger management, decision-making, etc.

I think Tiffany would benefit from participating in a group setting in which the topic of teen dating is focused on and specific beliefs about relationships are discussed in a peer environment with trained adult facilitation...

Finally, specific counseling interventions were recommended, the most common of which was solution-focused:

Since Anna has decided to seek help shows her strengths and willingness to accept there is an issue. Solution focus is goal-directed and focuses on the solution than the problem that brought Anna to this point.

I would possibly utilize Solution Focused combined with Strengths Model.

\section{Assessment}

Some MSW students indicated that they needed additional information to better understand and assess the situation with the dating couples. Approximately $25 \%(n=69)$ of the total coded responses included a recommendation about assessment in addition to or as a stand-alone method of intervention (i.e., double-coded alongside one of the additional themes). Assessment subthemes included the following: assess the goals for the current relationship $(n=20 ; 29 \%)$, assess the overall situation $(n=17 ; 24.6 \%)$, explore feelings $(n=15 ; 21.7 \%)$, assess the home environment and past ( $n=9 ; 13 \%)$, assess support systems $(n=5 ; 7.3 \%)$, and assess impact on school performance $(n=3 ; 4.4 \%)$. Examples relating to assessment of goals for the current relationship included:

List pros and cons to their relationship as well as a list of things that Ana wants to change in her relationship for the relationship to continue.

Explore motivation for maintaining the relationship.

Examples relating to the need to assess the overall situation included: 
I would ask open-ended questions to understand what Ana needs to feel safe with Tiffany.

Assess her feelings and home situation and go from there.

Examples relating to the need to assess the home environment and past included:

I would ask about prior relationships and also family and friend relationships that she has witnessed.

I would ask Angela how her childhood was and how problems got resolved.

\section{Other}

Safety planning $(7.9 \% ; n=22)$, notifying parents $(3.9 \%, n=11)$, referral $(3.2 \% ; n=9)$, school interventions $(1.4 \% ; n=4)$, and stating that they were unsure $(0.7 \% ; n=2)$ were coded as "other." Although we did not consider these responses prevalent enough to meaningfully convey themes, we include them given their importance as interventions (e.g., safety planning) and given the research question (e.g., referral, unsure).

\section{Discussion}

This study responds to a lack of research concerning graduating MSW students' preparedness to respond to adolescent dating violence. We were specifically interested in how students would respond to scenarios of TDV, including the types of interventions they would propose. We found that nearly one-third of recommendations focused on education. Within this theme, over one-quarter of students' recommendations pertained to healthy versus unhealthy relationships. Students also noted the importance of teaching about appropriate boundaries, issues of control and anger, self-esteem, and communication skills. Further, over one-quarter of recommendations focused on providing the dating couple with counseling, nearly half of which specified individual counseling. Finally, almost onequarter of recommendations pertained to assessment of a range of factors including the high school student's goals for the relationship, their feelings, and to gain information about their past or current home situation as a stand-alone intervention or in addition to another modality. Few comments identified specific TDV or intimate partner violence interventions, such as safety planning, or discussed engaging with the school to enhance educational opportunities or services focused on TDV provided to students at large.

A majority of recommendations identified individualized education interventions, most of which centered on teaching youth about healthy relationship dynamics. Correspondingly, education is an important role of social workers and an intervention that they are often comfortable in recommending and performing (Asquith, Clark, \& Waterhouse, 2005; Black et al., 2010; Hepworth, Rooney, Rooney \& Strom-Gottfried, 2013). It is a strength that graduating social workers would instruct clients on healthy relationships. However, an overemphasis on the individual as needing instruction neglects critical reflection on ecological contexts contributing to relationship dynamics, including modeling and acceptance of violent conflict resolution strategies by important role models in the lives of youth (Ball et al., 2012). The MSW students' emphasis on individualized 
education also aligns with the finding that over one-third of comments focused on counseling, a majority of which identified individual counseling as a preferred intervention. This was not surprising, as Black and colleagues (2010) similarly found that almost onethird of social work students' recommendations in a domestic violence scenario related to counseling. Social work students may view TDV, similar to IPV (Danis \& Lockhart, 2003), as a mental health problem. These results may be contextualized in part by our sample, as one university offered a macro track alongside four clinically focused tracks and the other did not offer a macro-focused track (rather, students could pursue micro/macro interests through integrated content and assignments). Although many graduating social workers in the U.S. are interested in direct clinical practice (Council on Social Work Education, 2010), social workers should be taught and should similarly teach youth to understand how violent relationship dynamics are inseparable from peer, family, and societal influences.

The finding that many of the students' recommendations focused on the need to conduct an assessment, and specifically assess the goals of the relationship, suggests that students want to understand more about a relationship, even a volatile and violent relationship, prior to or as a key component of their intervention work. This is aligned with best social work practice and confirms the need for health professionals, including social workers, to be trained in how to implement appropriate screening tools and assessment protocols for TDV specifically (Cutter-Wilson \& Richmond, 2011). It is concerning that few comments mentioned assessing the client's support systems given their importance in violent relationships (Goodman \& Smyth, 2011). Informal supports are often the most likely to offer guidance, instrumental, and emotional resources to survivors of partner violence. Social workers should tap into these resources, where available, to mitigate the harmful effects of abuse and to bolster the efficacy of formal help-seeking (see Goodman \& Smyth, 2011 for a review).

Social workers' one-on-one work with youth offers a critical opportunity to discuss the adolescent's safety. Thus, it is concerning that very few recommendations from MSW students pertained to safety planning. Safety planning with teens can increase their understanding of the risk of violence as well as provide youth with resources and supportive options to consider (Campbell, 2001). Further, some of the recommended interventions did not consider safety; for example, many recommendations focused on couple's counseling without contextualizing such responses in light of risk assessment. Partners in abusive relationships are likely not free to engage in the open exchange of feelings, highlighting this as an important content area for training of social workers. Further, some comments suggested notifying parents about the incident of TDV. Mandatory reporting requirements are not always clear (Broner, Embry, Gremminger, Batts, \& Ashley, 2013) but much of teens' reluctance to seek help for TDV is related to fear of their parents' responses (Ashley \& Foshee, 2005; Black, Weisz, Preble, \& Sharma, 2015). Establishing and maintaining trust is critical in working with teens experiencing dating violence.

Beyond working directly with the adolescent, social workers are called upon to work within and across ecological systems to serve in various roles including as macro-level change agents (Kirst-Ashman \& Hull, 2015). It is interesting that no student recommendations focused on advocating with school administration for student safety, 
including for protective orders, and the possible need for one student to transfer to another classroom or school (see Jackson et al., 2013). A lack of responses reflecting macro-level interventions may reflect the wording of the question asked (i.e., focusing on the intervention one would conduct). Still, social workers should be aware of their own state's policies concerning protective orders for adolescents, advocating on behalf of such policies as supported by research (Hoefer, Black, \& Ricard, 2015). Similarly, rather than advocate for school-level interventions, graduating MSW students in this study focused primarily on the provision of individual education and counseling aimed at improving the relationship health of youth. It is interesting to note that their emphases (e.g., healthy relationships, communication skills) parallel the tendency for TDV programs to deliver similar content (see Malhotra, Gonzalez-Guarda, \& Mitchell, 2015 and Whitaker et al., 2006 for reviews). A strength of this finding is that it suggests social workers may be using their advanced clinical knowledge to build relationship capacities with youth and may be well-suited for further training in the delivery of TDV interventions in the classroom.

\section{Limitations}

Findings need to be considered within the context of the limitations of the research study. The researchers developed the instrument for the purpose of the study and its validity and reliability were not assessed. The survey had a low response rate and only 73 of the 186 students completed the open-ended questions on the survey. It is not atypical to obtain high nonresponse rates in online surveys (typical rates ranging from 20 to 33\%; Nulty, 2008), and higher nonresponse rates in open-ended questions compared to other question formats (Millar \& Dillman, 2012). Students completing the survey could have been limited to those who had a special interest in the topic. We have no way of knowing if students did not know how to respond to the TDV vignettes or simply did not want to take the time to respond. It may have been that some did not see any problems presented by the vignettes, in which case asking them what intervention(s) they would recommend might have prompted non-response. Not asking whether there is a need for intervention may be considered a methodological limitation, although adolescents in each scenario addressed social workers directly for help.

Further, we asked students to speculate about how they would intervene in the TDV scenarios portrayed in the vignettes. However, how MSW students speculate they would intervene may differ from what they might actually do if faced with the situation. Many students in this study did report experience with middle school and high school youth, and some had received MSW coursework specific to TDV. How MSW students differed from one another with regard to their experience, training, and response to TDV is an area for future research, as is how social workers actually respond to TDV scenarios. Future research can also assess how students respond differently to incidences of TDV involving same-sex and heterosexual couples.

We surveyed MSW students in two public universities located in the same state in the southern part of the U.S. Although both student bodies were diverse, they were similar to each other. Additional research is needed in other parts of the U.S. and in other countries. 


\section{Conclusions}

Only two other publications that we are aware of have assessed helping professionals' (i.e., counselors' and nurses') knowledge and readiness to practice in contexts of TDV (Khubchandani et al., 2012, 2013). The present study has extended this research in two distinct ways: one, by surveying graduating MSW social work students, and two, by using open-ended qualitative methods to understand specifically how students would provide services to youth experiencing violence in their relationships. Our findings parallel the studies conducted by Khubchandani and colleagues $(2012,2013)$ in highlighting a need for further training specific to TDV, particularly in the areas of safety planning and meso- and macro- level practice.

Students' recommendations for education and counseling rather than safety planning or multi-level interventions indicate that social work programs need to provide specific content related to TDV and evidence-based interventions (see for example, Weisz \& Black, 2009), particularly in order to prepare those interested in serving youth. One concern is that many MSW programs do not currently have a specific course for inclusion of TDV content. We do not know how much content on TDV is embedded in Family Violence and IPV courses or in foundational HBSE and practice courses. Content could be included and embedded within foundational and practice courses covering curricula specific to the developmental period of adolescence (e.g., HBSE) and with practice vignettes such as those used in this study in order to assess practice competencies. Given the high prevalence of teen dating violence (Vagi et al., 2015), it is likely that social workers will come across this issue; it is important to prepare them to handle it effectively.

\section{References}

Ashley, O. S., \& Foshee, V. A. (2005). Adolescent help-seeking for dating violence: Prevalence, sociodemographic correlates, and sources of help. Journal of Adolescent Health, 36, 25-31. doi:https://doi.org/10.1016/j.jadohealth.2003.12.014

Asquith, S. Clark, C. L., \& Waterhouse, L. (2005). The role of the social worker in the 21st century: A literature review. Retrieved from http://www.gov.scot/resource/doc/47121/0020821.pdf

Ball, B., Tharp, A. T., Noonan, R. K., Valle, L. A., Hamburger, M. E., \& Rosenbluth, B. (2012). Expect Respect support groups: Preliminary evaluation of a dating violence prevention program for at-risk youth. Violence Against Women, 18(7), 746-762. doi:https://doi.org/10.1177/1077801212455188

Banyard, V. L., \& Cross, C. (2008). Consequences of teen dating violence understanding intervening variables in ecological context. Violence against Women, 14(9), 998-1013. doi:https://doi.org/10.1177/1077801208322058

Barnett, O. W., Miller-Perrin, C. L., \& Perrin, R. D. (2010). Family violence across the lifespan: An introduction. Thousand Oaks, CA: Sage.

Black, B. M., Weisz, A. N., \& Bennett, L. W. (2010). Graduating social work students' perspectives on domestic violence. Affilia, 25(2), 173-184. doi:https://doi.org/10.1177/0886109910364824 
Black, B. M., Weisz, A. N., Preble, K. M., \& Sharma, B. (2015). Parents' awareness of and anticipated responses to their teens' reports of dating violence. Journal of Family Social Work, 18(1), 3-20. doi:https://doi.org/10.1080/10522158.2014.968941

Broner N., Embry, V. V., Gremminger, M. G., Batts, K., \& Ashley, O. S. (2013, May). Mandatory reporting and keeping youth safe. Washington, DC: Administration on Children, Youth and Families, Family and Youth Services Bureau.

Campbell, J. C. (2001). Safety planning based on lethality assessment for partners of batterers in intervention programs. Journal of Aggression, Maltreatment \& Trauma, 5(2), 129-143. doi:https://doi.org/10.1300/J146v05n02_08

Cohn, F., Salmon, M. E., \& Stobo, J. D. (2002). Confronting chronic neglect: The education and training of health professionals on family violence. Washington, DC: National Academies Press.

Connor, P. D., Nouer, S. S., Mackey, S. N., Banet, M. S., \& Tipton, N. G. (2012). Overcoming barriers in intimate partner violence education and training of graduate social work students. Journal of Teaching in Social Work, 32(1), 29-45. doi:https://doi.org/10.1080/08841233.2012.641893

Council on Social Work Education. (2010). 2010 Statistics on social work education in the United States: A summary. Retrieved from http://www.cswe.org/File.aspx?id=52269

Creswell, J. W. (2007). Qualitative inquiry and research design: Choosing among five approaches ( $2^{\text {nd }}$ ed.). Thousand Oaks, CA: Sage.

Cutter-Wilson, E., \& Richmond, T. (2011). Understanding teen dating violence: Practical screening and intervention strategies for pediatric and adolescent healthcare providers. Current Opinion in Pediatrics, 23(4), 379-383. doi:https://doi.org/10.1097/MOP.0b013e32834875d5

Danis, F. (2004). Factors that influence domestic violence practice self-efficacy: Implications for social work. Advances in Social Work, 5(1), 150-161.

Danis, F. S., \& Lockhart, L. (2003). Guest editorial: Domestic violence and social work education: What do we know, what do we need to know? Journal of Social Work Education, 39(2), 215-224.

De Koker, P., Mathews, C., Zuch, M., Bastien, S., \& Mason-Jones, A. J. (2014). A systematic review of interventions for preventing adolescent intimate partner violence. Journal of Adolescent Health, 54(1), 3-13. doi:https://doi.org/10.1016/j.jadohealth.2013.08.008

Eaton, D. K., Davis, K. S., Barrios, L., Brener, N. D., \& Noonan, R. K. (2007). Associations of dating violence victimization with lifetime participation, co-occurrence, and early initiation of risk behaviors among U.S. high school students. Journal of Interpersonal Violence, 22(5), 585-602. doi:https://doi.org/10.1177/0886260506298831

Goodman, L. A., \& Smyth, K. F. (2011). A call for a social network-oriented approach to services for survivors of intimate partner violence. Psychology of Violence, 1(2), 79-92. doi:https://doi.org/10.1037/a0022977

Halpern, C. T., Oslak, S. G., Young, M. L., Martin, S. L., \& Kupper, L. L. (2001). Partner violence among adolescents in opposite-sex romantic relationships: Findings from the 
National Longitudinal Study of Adolescent Health. American Journal of Public Health, 91(10), 1679-1685. doi:https://doi.org/10.2105/AJPH.91.10.1679

Hepworth, D. H., Rooney, R. H., Rooney, G. D., Strom-Gottfried, K. (2013). Direct social work practice: Theory and skills (9th ed.)., Pacific Grove, CA: Brooks / Cole Empowerment Series.

Hoefer, R., Black, B., \& Ricard, M. (2015). The impact of state policy on teen dating violence prevalence. Journal of Adolescence, 44, 88-96. doi:https://doi.org/10.1016/j.adolescence.2015.07.006

Hutchinson, E. (2008). Dimensions of human behavior (3rd ed.). Los Angeles, CA: Sage.

Jackson, R. D., Bouffard, L. A., \& Fox, K. A. (2013). Putting policy into practice: Examining school districts' implementation of teen dating violence legislation. Criminal Justice Policy Review, 25, 503-524. doi:https://doi.org/10.1177/0887403412475136

Khubchandani, J., Price, J. H., Thompson, A., Dake, J. A., Wiblishauser, M., \& Telljohann, S. K. (2012). Adolescent dating violence: A national assessment of school counselors' perceptions and practices. Pediatrics, 130(2), 202-210. doi:https://doi.org/10.1542/peds.2011-3130

Khubchandani, J., Telljohann, S. K., Price, J. H., Dake, J. A., \& Hendershot, C. (2013). Providing assistance to the victims of adolescent dating violence: A national assessment of school nurses' practices. Journal of School Health, 83(2), 127-136. doi:https://doi.org/10.1111/josh.12008

Kirst-Ashman, K. K., \& Hull Jr, G. H. (2015). Brooks/Cole empowerment series: Generalist practice with organizations and communities. Independence, KY: Cengage Learning.

Lietz, C. A., \& Zayas, L. E. (2010). Evaluating qualitative research for social work practitioners. Advances in Social Work, 11(2), 188-202.

Lockhart, L. L., \& Danis, F. S. (2010). Domestic violence: Intersectionality and culturally competent practice. New York: Columbia University Press.

Malhotra, K., Gonzalez-Guarda, R. M., \& Mitchell, E. M. (2015). A review of teen dating violence prevention research: What about Hispanic youth? Trauma, Violence, \& Abuse, 16(4), 444-465. doi:https://doi.org/10.1177/1524838014537903

McMahon, S., Postmus, J. L., Warrener, C., Plummer, S., \& Schwartz, R. (2013). Evaluating the effect of a specialized MSW course on violence against women. Journal of Social Work Education, 49(2), 307-320.

Millar, M., \& Dillman, D. (2012). Do mail and internet surveys produce different item nonresponse rates? An experiment using random mode assignment. Survey Practice, 5(2). Retrieved from http://www.surveypractice.org/index.php/SurveyPractice/article/view/48/html

National Conference of State Legislatures. (2016). Teen dating violence. Retrieved from http://www.ncsl.org/research/health/teen-dating-violence.aspx

Nulty, D. D. (2008). The adequacy of response rates to online and paper surveys: What can be done? Assessment \& Evaluation in Higher Education, 33(3), 301-314. doi:https://doi.org/10.1080/02602930701293231 
Pomeroy, E., Parrish, D. E., Host, J., Cowlagi, G., Cook, P., \& Stepura, K. (2011). Educating students about interpersonal violence: Comparing two methods. Journal of Social Work Education, 47(3), 525-544. doi:https://doi.org/10.5175/JSWE.2011.200900077

Postmus, J. L., McMahon, S., Warrener, C., \& Macri, L. (2011). Factors that influence attitudes, beliefs, and behaviors of students toward survivors of violence. Journal of Social Work Education, 47(2), 303-319. doi:https://doi.org/10.5175/JSWE.2011.200900122

Silverman, J. G., Raj, A., Mucci, L. A., \& Hathaway, J. E. (2001). Dating violence against adolescent girls and associated substance use, unhealthy weight control, sexual risk behavior, pregnancy, and suicidality. Journal of American Medical Association, 286(5), 572-579. doi:https://doi.org/10.1001/jama.286.5.572

Smith, G. A., Baum, C. R., Dowd, M. D., Durbin, D. R., Quinian, K. P., Sege, R. D., ... \& Wright, J. L. (2009). Policy statement-role of the pediatrician in youth violence prevention. Pediatrics, 124(1), 393-402. doi:https://doi.org/10.1542/peds.2009-0943

Texas H.B. $121 \S 37-0831$ (2007). Retrieved from http://www.legis.state.tx.us/tlodocs/80R/billtext/html/HB00121F.HTM

Tower, L. E. (2003). Domestic violence screening: Education and institutional support correlates. Journal of Social Work Education, 39, 225-235.

Vagi, K. J., Olsen, E. O. M., Basile, K. C., \& Vivolo-Kantor, A. M. (2015). Teen dating violence (physical and sexual) among US high school students: Findings from the 2013 National Youth Risk Behavior Survey. JAMA Pediatrics, 169(5), 474-482. doi:https://doi.org/10.1001/jamapediatrics.2014.3577

Weisz. A. N., \& Black, B. M. (2009). Programs to reduce teen dating violence and sexual assault: Perspectives on what works. NY: Columbia University Press.

Whitaker, D. J., Morrison, S., Lindquist, C., Hawkins, S. R., O'Neil, J. A., Nesius, A. M., ... $\&$ Reese, L. R. (2006). A critical review of interventions for the primary prevention of perpetration of partner violence. Aggression and Violent Behavior, 11(2), 151-166. doi:https://doi.org/10.1016/j.avb.2005.07.007

Zastrow, C., \& Kirst-Ashman, K. K. (2010). Understanding human behavior and the social environment. Belmont, CA: Brooks/Cole, Thomson Learning.

\section{Author note:}

Address correspondence to: Heidi Adams Rueda, MSW, PhD, Department of Social Work, The University of Texas at San Antonio, 501 W. César E. Chávez Blvd., San Antonio, TX, 78207, 210-458-2309, Heidi.rueda@utsa.edu 


\section{Appendix}

\section{Scenario}

\section{Background Information:}

Tiffany and Ana have been dating for 3 months. Ana is in the $9^{\text {th }}$ grade, is in cross-country track, and likes to run every day after school. Tiffany is in the $10^{\text {th }}$ grade, and does not participate in any school activities. This is both Tiffany and Ana's first relationship, although Tiffany has experimented a little bit sexually with both girls and guys. Ana is also unsure about whether her sexual preference is just for females, and had told Tiffany that when they first hung out. Both Ana and Tiffany are Caucasian.

\section{The Situation:}

Over the last month, Tiffany has become more and more possessive of Ana and insists that she be with her at all times when not in class. One day Tiffany threatens to end the relationship if Ana does not hang out with her after school. Ana is upset that Tiffany has asked her to do this, but decides that missing one cross-country practice won't matter too much. While "chilling" at the donut shop, Tiffany and Ana have fun laughing with each other and hanging out with the other teens. Although Ana had a good time, the next day when Tiffany approaches her in the halls asking her to go again, Ana gets upset that missing two practices would mean she couldn't participate in the next cross-country meet. Tiffany insists that she come, and tells her that as her girlfriend she needed to be with her over her other friends. Tiffany states that she loves Ana, and that she couldn't bear to live without her since her home life is so bad.

Ana ends up having to drop out of the cross-country team to accommodate Tiffany's demands. She notices that Tiffany becomes jealous easily when she talks with any guys or girls. Tiffany has also asked for her Facebook and Twitter passwords and, because she wanted Tiffany to trust her, Anna gave them to her. Anna is upset, however, to see that Tiffany is constantly on her pages to see what she is posting and has even deleted some of her pictures with other friends. Tiffany begins to yell at Ana in front of their friends at the donut shop over small things, and calls her names like "slut" and "whore" when she talks to guys. Ana is afraid of Tiffany's growing possessiveness and anger towards her. Ana misses her old friends, and misses running in cross-country, but she is afraid that she is all Tiffany has. She remembers Tiffany's threat of "I don't know what I would do if you left me." Could it mean that Tiffany might hurt herself, or Ana, if she tried to leave?

Ana decides to seek help from you, the school social worker. She tells you that she doesn't want Tiffany to be upset with her anymore and that she doesn't know what to do. She want to be free to do other things besides hang out with her, but still wants to work out their relationship; after all, she does like being together when Tiffany is not mad at her.

\section{Scenario 2}

\section{Background Information}

Edgar and Angela are in $10^{\text {th }}$ grade and have been dating for 5 months. This is the longest relationship either of them has been in, and they consider it "serious". They are not sexually active, but they have been considering it for the last month. Angela gets jealous easily, and has been known to pinch Edgar and throw objects at him when they fight; Edgar does not consider it violence since she is a girl. Both Edgar and Angela are $2^{\text {nd }}$ generation Mexican Americans.

\section{The Situation:}

Edgar and Angela decide to go to the school dance together held that Friday at 6pm. They agree that since Angela has to work that night that she will meet Edgar in the school lobby around $7 \mathrm{pm}$ after she gets off and has a chance to go home and change.

On the night of the dance, Edgar arrives at 6:30pm and waits for Angela for about 15 minutes in the school lobby while chatting with a few of his friends who are already there. Hungry, he decides to grab a quick bite to eat with his friends that are heading into the gymnasium where the dance is taking place. At 6:45pm Angela arrives (15 minutes early) to find that Edgar is not waiting for her in the lobby as he had promised. She becomes angry after waiting for 5 minutes alone and decides to go look for Edgar inside the gym. Angela finds Edgar and a friend, Erica, laughing by the snacks table. Angela goes to Edgar and yells at him. Edgar tries to explain that he was just about to go back out to the lobby to be there by 7pm, like they had agreed, but Angela cuts him off - "I see how it is, you would rather eat with this tramp than wait for your girlfriend like you said you would!" She then slaps Edgar's arm and storms away, walking quickly to the school parking lot where she starts to cry.

Edgar is embarrassed that Angela hit him, and extremely angry that she did it in front of so many people at the dance. He doesn't know what to do, but decides to go after Angela to make sure she is okay. He sees her crying in the parking lot; she tells that him that she is sorry and that she was just jealous of Erica. Edgar tells her that he forgives her, but that he is starting to doubt if she is serious about their relationship since she keeps embarrassing him in public. He then pressures her to have sex that night, telling her that she needs to prove how sorry she is, and how much she really loves him. The next day, she is deeply upset about what happened and feels she wasted her virginity on Edgar. The next day of school she approaches her school social worker, explaining all that has happened. She does not want to leave the relationship, but does not want to feel pressured to keep sleeping with him. 